\title{
THE INTEGRATION OF 3D SPATIAL AND NON - SPATIAL COMPONENT FOR STRATA MANAGEMENT
}

\author{
Faraliyana Mohd Hanafi*, Muhammad Imzan Hassan \\ Faculty of Built Environment and Surveying, \\ University Technology Malaysia (UTM) \\ faraliyanahanafi@gmail.com*,imzan@utm.my
}

KEY WORDS: Cadastre, IndoorGML, strata title, geodatabase, data model, 3D model.

\begin{abstract}
:
Nowadays, due to rapid development and large populations especially in urban areas has caused indoor spaces of buildings becomes bigger and more complex. In most developing countries, the needs of advance cadastre systems and land administration are vital due to rapid development and large population area especially in the city centre such as Kuala Lumpur. More populations have caused more limited space, which explains the need to build a more vertical building. Due to this, an efficient strata management are required for managing the strata title. A study of country-based profile on cadastre domain standard has been conceptualized for land administration in Malaysia that allows integration of 2D and 3D representation of spatial units with supports of both formal and informal Rights, Restrictions and Responsibilities (RRR). Since this research used Malaysia cadastre management as a case study, the proposed model for the Malaysian land administration country profile was embedded in the integration model. Meanwhile, a new working item proposal for LADM Edition II has been introduced on the idea of encoding further integration of land administration with an existing standard such as IndoorGML. Hence, this paper proposes a conceptual model on the integration between both legal space (indoor) and legal object using LADM Edition II and IndoorGML standards for strata purposes. Three objectives had been recognized to achieve the aim of the study. Firstly, to identify the integration of spatial components and non-spatial components for strata management. The second is to develop a conceptual data model for strata with the integration of LADM Edition II and IndoorGML and lastly, is to develop a prototype to validate the proposed conceptual data model. Thus, the development of the conceptual model may provide insights or ideas for future work and land administration on strata purposes.
\end{abstract}

\section{INTRODUCTION}

According to the FIG (1995), Cadastre is generally a parcel based, and up to date land information system that holds the record of interest inland. For example, the rights, restrictions, and responsibilities (RRR). It usually includes the geometric description of land parcels that linked to other records contains the information of the parcel, the ownership, the values, and its improvement. Moreover, it is established for several reasons such as for fiscal purposes in valuation and impartial tax assessment, legal purposes such as in preparing documents for the conveyance of property. Besides that, it also used to accommodate, planning and other administrative purposes in the management of land also land use and enables sustainable development and environmental protection.

\subsection{Cadastre System in Malaysia}

Malaysian Cadastre System has based on the Torrens system that originated from Australia, which applied in their land administration system (Yusoff, 2013). The cadastre system in Malaysia was managed by a two-separated agency called the National Mapping Agency (NMA) and Land Office (LO). It is consists of two components that is the cadastral survey and land administration. Department of Survey and Mapping Malaysia (DSMM) or the Jabatan Ukur dan Pemetaan Malaysia (JUPEM) is the local authority that holds the responsibility as a spatial data custodian of cadastral data in Malaysia. They are the cadastral, mapping and geodetic data center providers to public agencies as well as the public. DSMM uses a high accuracy data survey to determine the location, dimension, and size of cadastre objects or properties to produce a Certified Plan (CP) as shown in Figure 1, (Hassan, 2017). DSMM has developed an application system development called eKadaster, which has been one of the world's most advanced measuring systems and is now a regional reference for Malaysia used. It is claimed that the system managed to shorten the process of measurement and provision of land-based property from two years to two months or less.

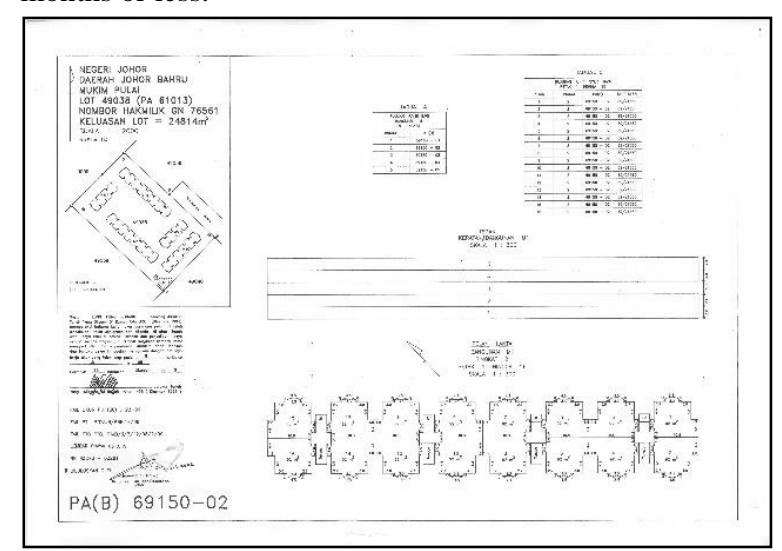

Figure 1. Example of Certified Plan (CP)

At the same time, the State authority (Land Office) entrusted with the development of eTanah. The objective of eTanah system is to develop a coordinated land management system through the full use of Information and Communication Technology (ICT) to enhance the delivery system of land transactions and other related services to the public. However, both of the systems work separately under two different organizations. An independent system, which is still in a 2D platform (Zulkifli et al., 2014). 


\section{LAND ADMINISTRATION}

Land Administration defined as the process of recording and disseminating information about the ownership, value, and use of land and its associated resources. The process also includes the determination of rights, other attributes of the land, the survey and description, detailed documentation, and the provision of relevant information used to support the land market (ECE, 1996).

\subsection{Strata Title}

Strata title are separate individual titles issued to units of houses, apartments or offices jointly developed within a development that shares common facilities such as gated \& guarded, security, car parks, and facilities governed by a common deed of mutual covenants. Under the Strata Title Act 1985, developers are required to apply for the strata titles on behalf of the purchasers (Kwong, 2011). The strata title is also important in managing the Rights, Restrictions, and Responsibility (RRR) of strata parcels. In an indoor environment, RRR on a part of a floor or a building can influence the accessibility and can significantly change the set of cells that can be used to derive a network.

Right is a formal or informal entitlement to own, to do something, or to refrain from doing something. There are two types of right of ownership that is freehold and leasehold property. Restriction, however, is an entitlement to refrain from doing something. A building administration may impose all kinds of restrictions and on the use of the building. For example, Shopping malls, which consist of areas in which all visitors are welcome, areas available for employees of the specific shop, and areas that are accessible for maintenance/cleaning services only (Zlatanova et al., 2016). Responsibility is an obligation to do something such as paying for the land tax. It is crucial for the developer to state the responsibility for each lot parcel owner to pay for the amount charged and the service provided (Hashim, 2018).

\subsection{Land Administration Data Model (LADM)}

LADM is an international standard published by the ISO (International Organization of Standardization) in 2012. The Technical Committee called ISO/TC 211, Geographic information and Geomatics, has prepared it and called it as ISO 19152. On top of that, LADM covers the basic information related to land administration components, which include the elements below and above the Earth's surfaces. It provides an abstract conceptual data model that represents four packages which are parties (people and organizations), RRR (ownership), spatial unit (parcel, legal space, and utility network) and also spatial sources (surveying) and spatial representations (geometry and topology). LADM data model is represented using the Unified Modelling Language (UML) class diagram that consists of three main packages, which are Party Package, Administrative Package, and Spatial Unit Package.

The establishment of LADM (ISO 19152:2012) allows the integration of legal space, which has its geometry that is sometimes not equal to its physical object. Legal space should be related to a physical object (Lemmen et al., 2018). Open Geospatial Consortium (OGC) has provided a variety of standard or open data models used to define physical space such as Geography Markup Language (GML), CityGML and IndoorGML. Applying LADM allows the assigning of RRR in indoor space that is used to indicate access rights for a different user. With the combined used of these standards, it covers a broad range of information classes which are the indoor 3D cell spaces, the connectivity, spatial units and boundaries, rights and restrictions and people (Alattas et al., 2017). An IndoorGML - LADM is one of the recent examples of the combination of indoor space and legal object.

\subsubsection{Basic Classes of LADM}

The core LADM based on four basic classes as shown in Figure 2:

- Class LA_Party: Instances of this class are parties.

- Class LA_RRR: Instances of subclasses of LA_RRR are rights, restrictions or responsibilities.

- Class LA_BAUnit: Instances of this class are basic administrative units.

- Class LA_SpatialUnit: Instances of this class are spatial units.

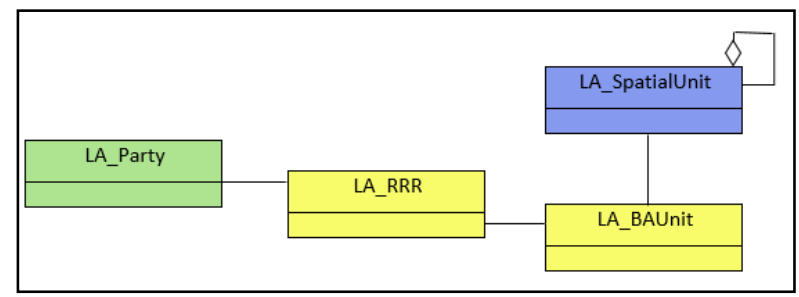

Figure 2. Basic Classes of LADM

\subsubsection{Party Package}

The main class of the Party Package is the basic class LA_Party (with a party as an instance). LA_Party has a specialization: LA_GroupParty (with group party as an instance). Between LA_Party and LA_GroupParty there is an optional association class: LA_PartyMember (with party member as an instance). Figure 3 shows the relationship between LA_Party and LA_Group Party associated with LA_PartyMember.

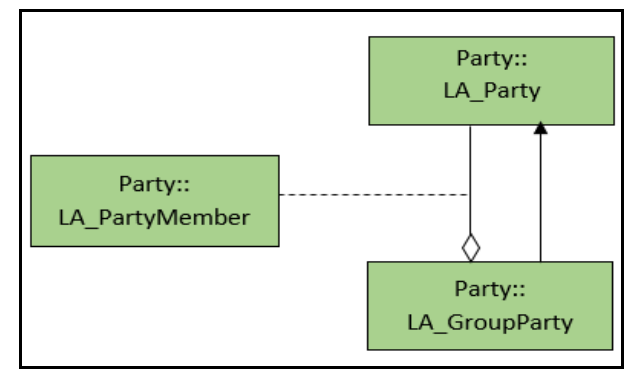

Figure 3. Classes of Party Package

\subsubsection{Administrative Package}

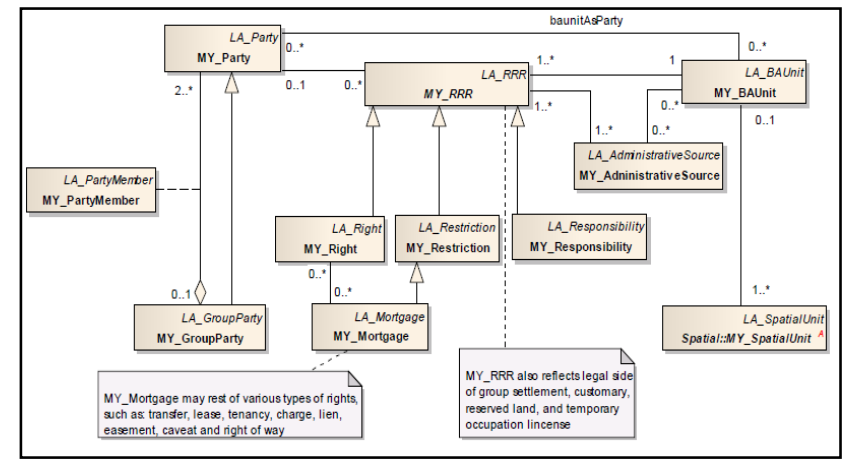




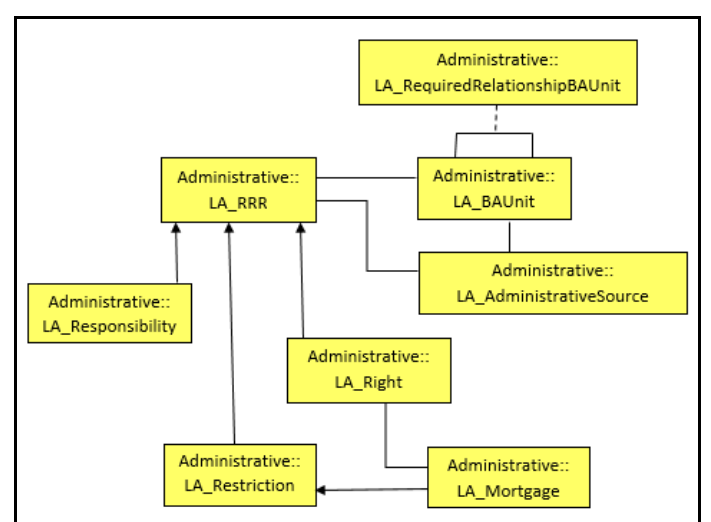

Figure 4. LADM Administrative and Classes Package

\subsubsection{Spatial Unit Package}

The main class of the Spatial Unit Package is the basic class LA_SpatialUnit, with spatial units as instances. The classes involved in Spatial Unit Package are shown in Figure 5.

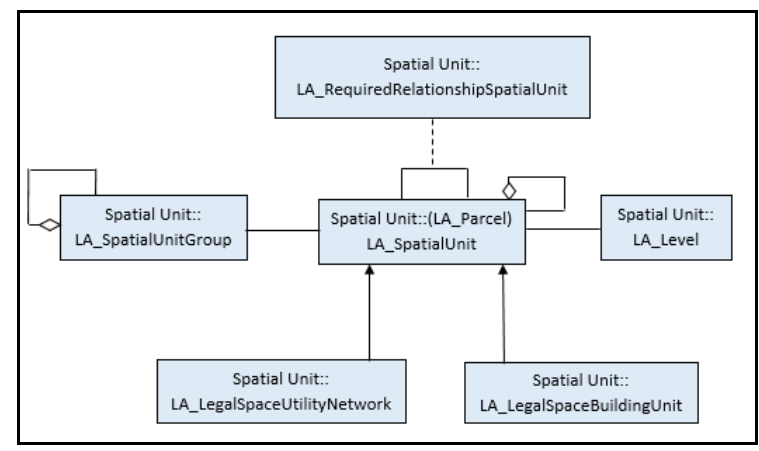

Figure 5. Classes of Spatial Unit Package

\subsection{Malaysian LADM Country Profile}

In related work, Zulkifli, et al. (2014) have proposed a conceptual model describing the development of a prototype for the assessment of the Malaysian LADM country profile. The Malaysian LADM country profile consists of two parts: administrative shown in Figure 6 and also the spatial part. It uses "MY_" as the prefix to describe the model and it represents $2 \mathrm{D}$ and $3 \mathrm{D}$ situations, which covers related agencies in Malaysia. The integration of LADM and IndoorGML will be based on the Malaysian LADM Country Profile.

\subsection{LADM Edition II}

LADM is an ongoing development that requires more improvement and revision since it supports a wide variety of regulatory and policy environments. As what has been discussed during LADM Workshops in Delft, The Netherlands in March 2017 and in Zangreb, Croatia in April 2018. According to Lemmen, et al. (2018), LADM improvements and extensions are needed as well as LADM process models such as to include the valuation/ taxation extension or moving informative code list values to normative parts of the standard and adding semantic technologies for more precise defining code list.

LADM Edition I do not include Land Administration processes for initial data acquisition, data maintenance and data publication (Lemmen, et al., 2018). The key to the improvement of LADM Edition II is the ability to support the regulatory and policy environments that are unique to individual jurisdictions and nations. Generally, several things have been discussed in terms of cooperation, communication, common vision on use and applications of standards in land administration and compatibility.

Listed down below is the improvement of the current conceptual model that related to the research:

- $\quad$ Linking physical object

- Legal space and legal objects have their geometry which is in many cases not (not completely) equal to physical space and physical objects.

- Legal space should be linked to physical objects using ID's or by reuse descriptions of space.

- GML and CityGML offer options in this respect.

- Indoor models

- The users of the indoor space create a relationship with the space depending on the type of the building and the function of the spaces.

- Applying LADM allows assigning rights, restrictions, and responsibilities to indoor spaces, which indicates the accessible spaces for each type of user.

- An IndoorGML-LADM model is one example of linking physical and legal objects.

\subsection{D Object Identifier}

There are two types of identifier used related to cadastre management in Malaysia called as a Unique Parcel Identifier (UPI) and Unique Feature Identifier (UFI). Further explanations on both identifiers is listed below.

\subsubsection{Unique Parcel Identifier (UPI)}

UPI is crucial in matters related to land and strata since it is used to describe each land parcel individually. Code for each UPI is determined by the JUPEM with 16 characters according to State, District, Town / City, Sections and Lot No. Table 1 below shows the example of UPI code for lot no 49038.

\begin{tabular}{|c|c|c|c|c|c|}
\hline State & District & Town/City & Section & Lot No. & UPI \\
\hline Johor & Johor Bahru & Pulai & - & & \\
\hline 01 & 02 & 03 & 000 & 0049038 & 0102030000049038 \\
\hline
\end{tabular}

Table 1. Example of UPI code

\subsubsection{Unique Feature Identifier (UFI)}

UFI is a code that consists of 26 characters with an additional 10 characters of UPI used to describe $3 \mathrm{D}$ cadastre in Malaysia. It was introduced by (Hassan \& Rahman, 2011) to represent multi-level buildings such as Apartments and commercial buildings. Example of UFI code for a particular lot number with additional information on Building, Floor, and Plot is shown in Table 2 below.

\begin{tabular}{|c|c|c|c|c|c|c|c|}
\hline State & District & $\begin{array}{c}\text { Town } \\
\text { City }\end{array}$ & Section & Lot No. & Building & Floor & Plot \\
\hline Johor & Johor Bahru & Pulai & - & - & - & - & - \\
\hline 01 & 02 & 03 & 000 & 0049038 & M01 & 001 & 001 \\
\hline UFI & $0102030000049038 \mathrm{M} 01001001$ \\
\hline
\end{tabular}

Table 2. Example of UFI code 


\section{THE STANDARD FOR INDOOR SPACE MODELING}

There are a variety of data standards provided in describing indoor space, which is before IndoorGML that is BIM/IFC, GML, CityGML, LandXML, IndoorGML, etc.

Each standard has its own users and purposes. For example, the basic goal of CityGML is to reach a common definition of basic entities with attributes and relationship in 3D city model using common feature model while IndoorGML provides a common indoor space model using cellular space model (Li et al., 2016).

There are also Industry Foundation Classes (IFC) standards, which serve to describe building and construction industry data. It is an object-based file format with a data model developed by building SMART to facilitate interoperability in the architecture, engineering, and construction (AEC) industry, and is a commonly used collaboration format in Building Information Modelling (BIM) based projects. Hence, this paper is focusing on the OGC IndoorGML standards that use a cell space model to represent indoor space.

\subsection{IndoorGML}

IndoorGML is an OGC standard for an open data model and XML schema for indoor spatial information. It aims to provide a common framework of representation and exchange of indoor spatial information. It is defined as an application schema of OGC Geographic Markup Language (GML) 3.2.1 (Jiyeong Lee, 2018a).

The goal of IndoorGML is to represent and allow for the exchange of geoinformation that is required to build and operate indoor navigation systems. Several standards such as CityGML, KML, and IFC have been published to describe 3D geometry and semantics of buildings not only for outdoor space but also for also indoor space, but they lack important features that are required by indoor navigation applications. This standard aims to provide complementary and additional encoding features for indoor spatial information required for indoor navigation.

IndoorGML is intended to provide the following functions:

- Representing the properties of indoor space, and

- Providing spatial reference of features in indoor space.

\subsubsection{Aspects of IndoorGML}

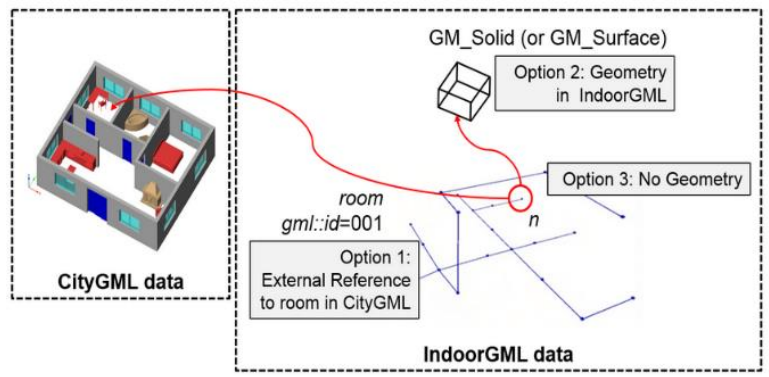

Figure 8. IndoorGML core model (Jiyeong Lee, 2018a)

An important difference in indoor space from outdoor is that indoor space is composed of complicated constraints such as corridors, doors, stairs, elevators, etc. Indoor space as a set of cells, which are defined as the smallest organizational or structural unit of indoor space. Cellular space has important properties. First, every cell has an identifier (namely gml_id) such as room number. Second, each cell may have a common boundary with others but does not overlap with other cells. Third, position in cellular space can be specified by cell identifier, although we may employ $(\mathrm{x}, \mathrm{y}, \mathrm{z})$ coordinates to specify a position for a more precise location.

Semantic is an important characteristic of cells. In IndoorGML, semantics is used for two purposes: to provide classification and to identify a cell and determines the connectivity between cells. Semantics allows defining cells, which can be of importance for navigation. For example, the most commonly used classification of cells in topographic space is into navigable (rooms, corridors, doors) and nonnavigable (walls, obstacles) cells.

The geometric representation of $2 \mathrm{D}$ or $3 \mathrm{D}$ features in indoor space does not belong to the major focus of IndoorGML, since they are clearly defined by ISO 19107, CityGML, and IFC. However, for the sake of self-completeness, the geometry of $2 \mathrm{D}$ or $3 \mathrm{D}$ object may be optionally defined within IndoorGML according to the data model defined by ISO 19107. There are three options to represent the geometry of a cell in IndoorGML shown in Figure 7.

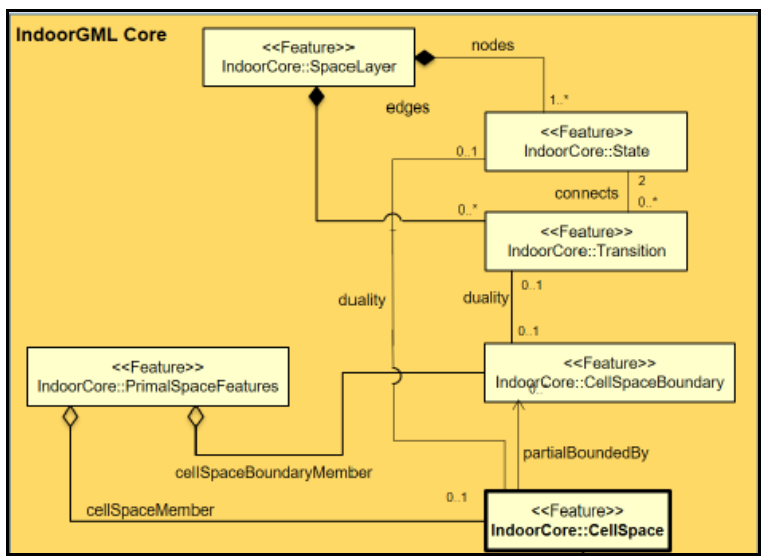

Figure 7. Geometry in IndoorGML (Jiyeong Lee, 2018a)

but they may be comprised of multiple buildings or a complex of connected buildings (Jiyeong Lee, 2018b). The IndoorGML core module (Figure 8) defines the basic components of the IndoorGML data model. It includes the schema definitions of basic classes for cells, dual spaces and multi-layered space models. It is an application schema of GML 3.2.1.

\section{RESEARCH METHODOLOGY}

In the development of the conceptual data model based on LADM, several phases need to be done to achieve the objectives of the research. Figure 9 shows the steps required to fulfill research objectives. 


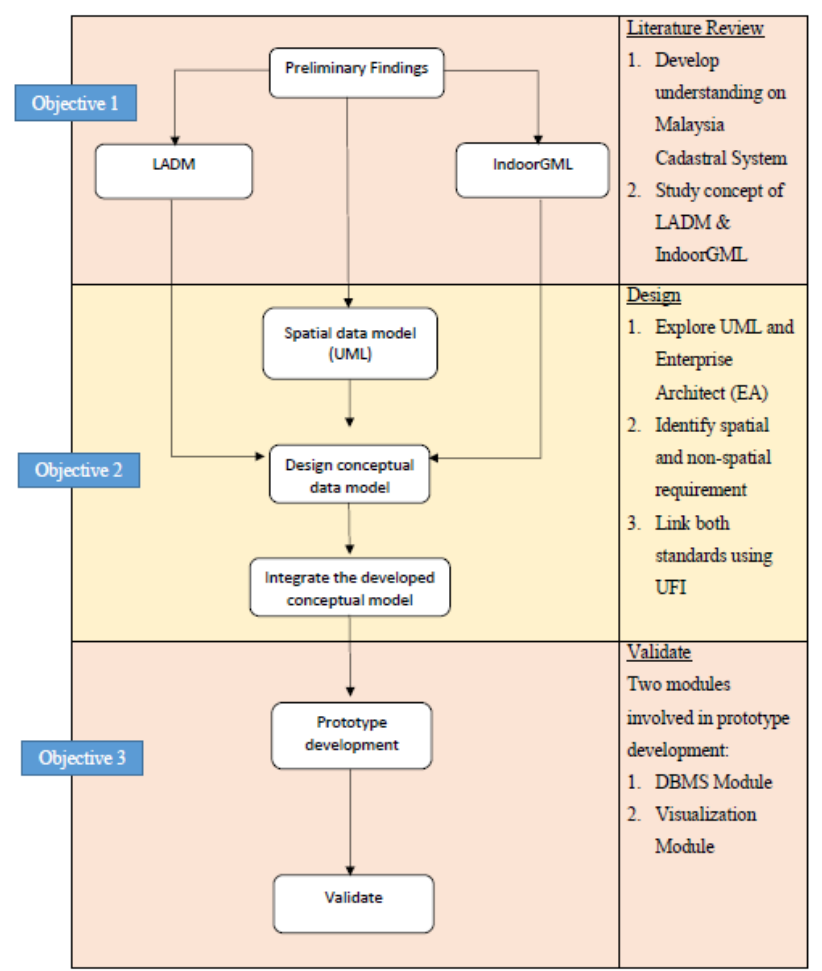

Figure 9. Flowchart of research methodology

\subsection{Preliminary Research}

From the literature review, Malaysia is still working towards the $3 \mathrm{D}$ cadastre that covers the strata development. DSMM is responsible for the spatial component of the land parcel where it holds the first-class accuracy in surveying. While LO holds the responsibility in managing the attributes and information about the parcel. Unfortunately, both of the agency has separated system called as eKadaster and eTanah. From that, (Hassan, 2017) has come up with the idea of integrating both of the system using Unique Parcel Identifier (UPI). The integration of the system using UPI is shown in Figure 10.

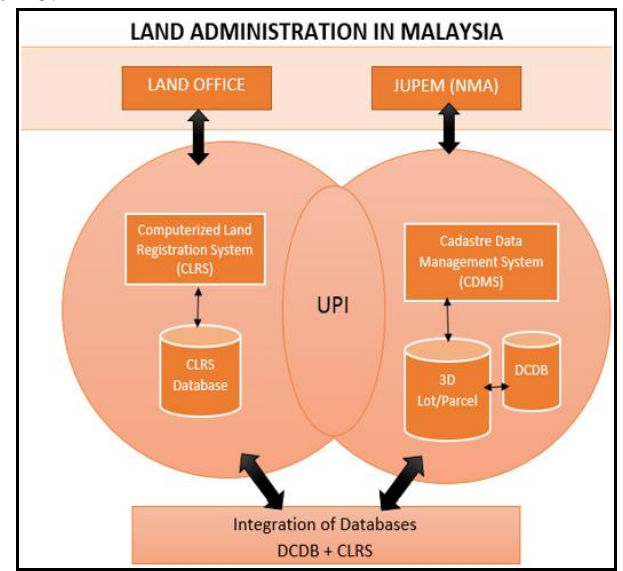

Figure 10. Integrating system using UPI

\subsection{Spatial component of IndoorGML}

The spatial component consists of the Spatial Unit Packages based on Malaysian based country profile and IndoorGML core consist of Cell space, PrimalSpaceFeature, CellSpaceBoundary, Space Layer, State, and Transition. Figure 11 shows the spatial component involved including the IndoorGML.

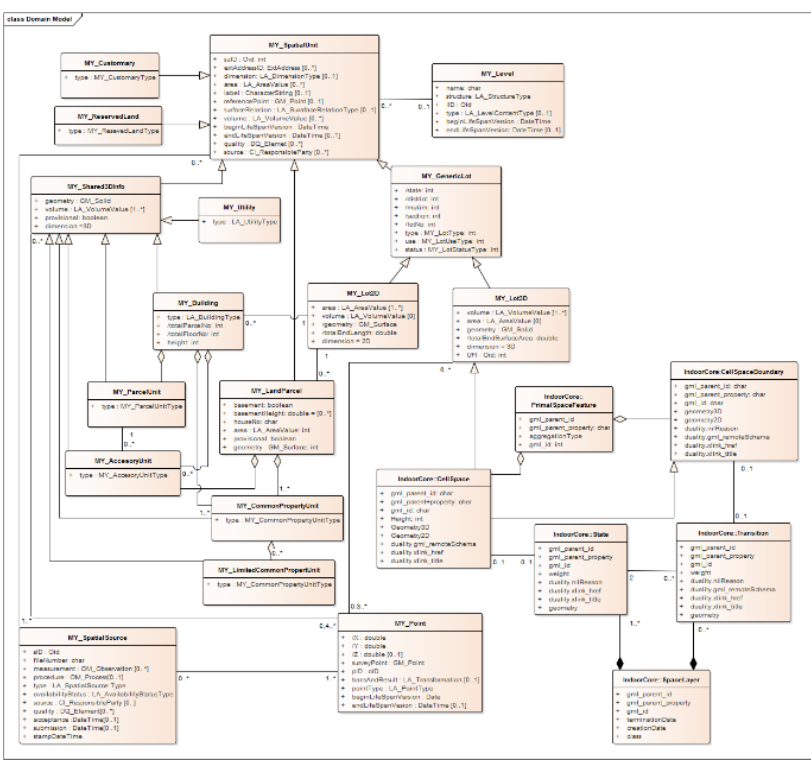

Figure 11. Spatial Component data model

\subsection{Non-spatial component of LADM}

The non-spatial component consists of object classes used in LADM. The administrative packages related to an abstract class of MY_RRR with three main subclasses called MY_Right, MY_Restriction, and MY_Responsibility. A subclass of MY_Mortgage is inherited by MY_Restriction associated with MY_Rights MY_BAUnit classes are used to register the basic property units, which consists of several spatial units belongs to a party under the same rights. It has a unique identifier when registered or recorded but it can consist of zero spatial units when the registry exists but not a cadastre. MY_AdministrativeSource as it holds the document as evidence showing the rightful owner. It is also used to describe and transaction (deed) or judgement of register holder. MY_AdministrativeSource is associates with MY_RRR and MY_BAUnit. Figure 12 shows the non-spatial component involved in the data model.

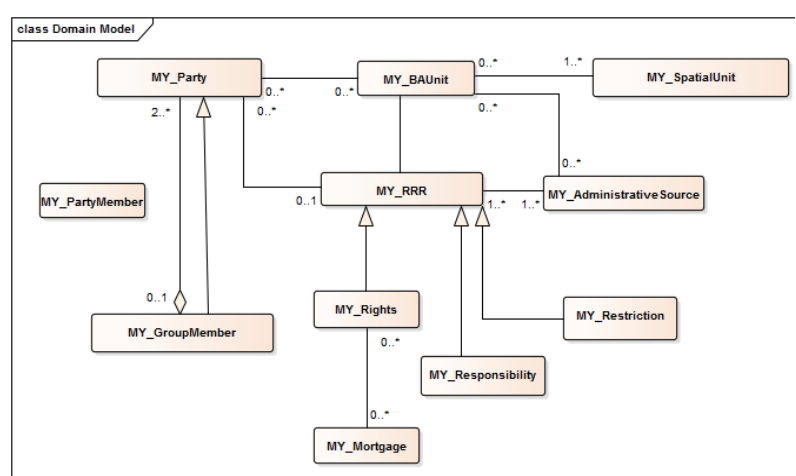

Figure 12. Non-spatial component data model

\subsection{Integration of LADM and IndoorGML}

The integration was made using the identifier called 'gml_id' represent by UFI, is used as a cell identifier for each legal space. The spatial unit represented by blue color serves as an IndoorGML act as an extension within LADM. While yellow color instances represent administrative package in LADM and party packages are represented in green. MY_SpatialUnit which consists MY_GenericLot is based on Malaysian LADM Country Profile, and IndoorGML was embedded 
under the MY_Lot3D. It is because the indoor space represented as a 3D spatial object. Each class in Indoor Core has gml_id as an identifier to each cell space used to link with the Spatial Unit with the LADM geospatial database. The attributes for each class in IndoorCore retrieved from the development of the 3D model. The combined model of LADM and IndoorGML using Unique Feature Identifier (UFI) as shown in Figure 13.

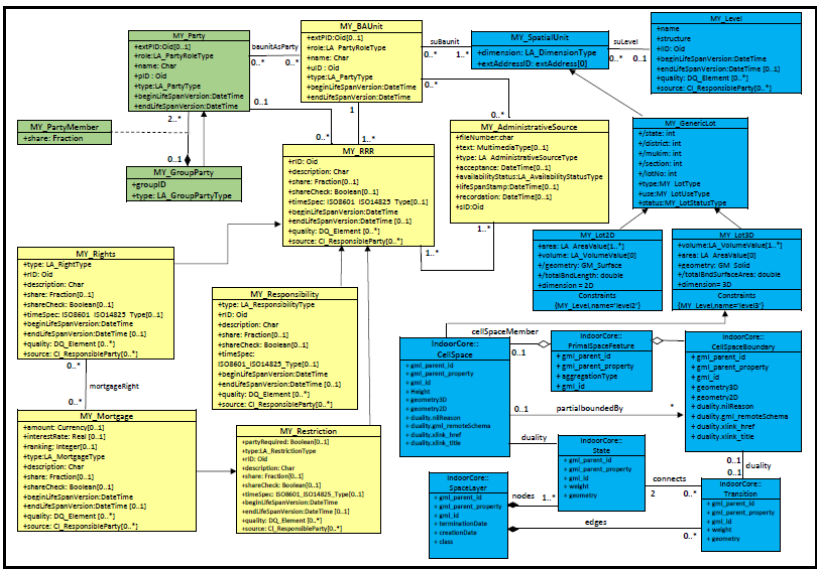

\section{RESULT AND ANALYSIS}

After all the process of the methodology being done, the conceptual model is tested in producing the prototype using a building from Melana Apartment, Skudai. A simple query has been made as an analysis to validate the proposed model shown in Figure 13.

\subsection{D Model Development}

The 3D model is generated using Java IndoorGML Editor (JINEditor) software developed by STEM Lab of Pusan National University available on GitHub. An open-source Java program provides tools for simple editing IndoorGML data. Quantum GIS (QGIS) was chosen at first to be the platform of integration but the failure in modeling the 3D building makes ArcScene an eligible software to be used.

To produce the $3 \mathrm{D}$ model, a $2 \mathrm{D}$ certified plan $(\mathrm{CP})$ is used as a reference for the building. The apartment consists of five (5) stories with three (3) meters ceiling height. There is a total of 64 house units for 4 levels of Melana Apartment. The properties of the building are entered in the JINEditor software and the coordinates are based on Lower Corner and Upper Corner of the building act as a boundary for the parcel. Floorplan properties in JINEditor only allowed for an image file (i.e. jpg and png). To make sure that the model is geometrically correct, the image was rectified and saved to jpg format. Table 3 shows the properties entered in JINEditor.

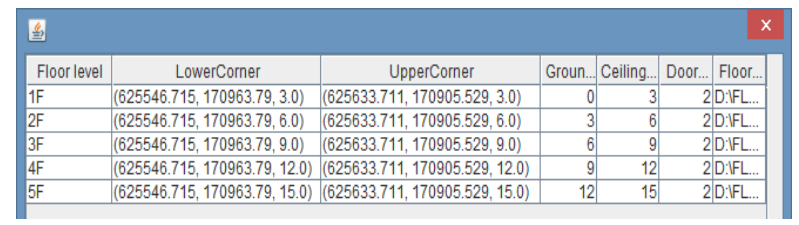

Table 3. Properties of building in JINEditor

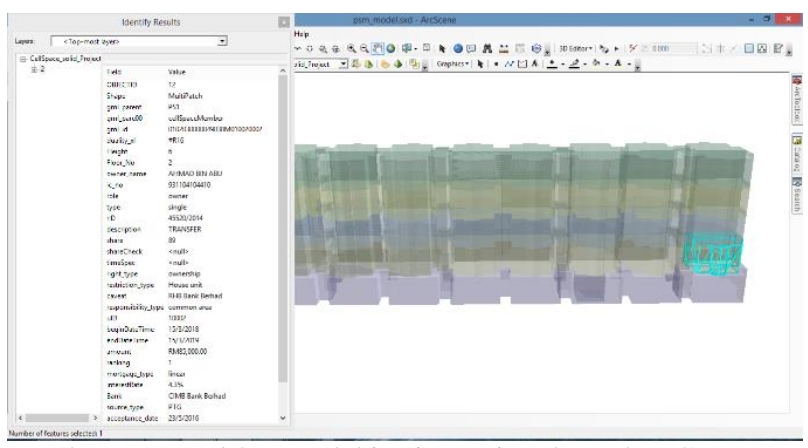

The generated 3D Model is view using the IndoorGML viewer and each cell space is identified using the UFI shown in Figure 14.

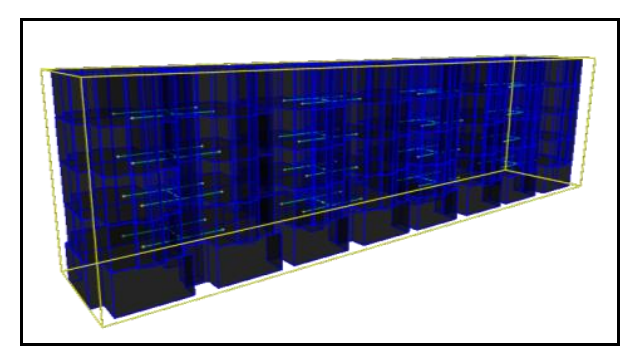

Figure 14. Generated 3D model using IndoorGML

The actual encoding of the 3D Parcel in the XML standard format shown in Figure 15 depicts all the information about each cell space.

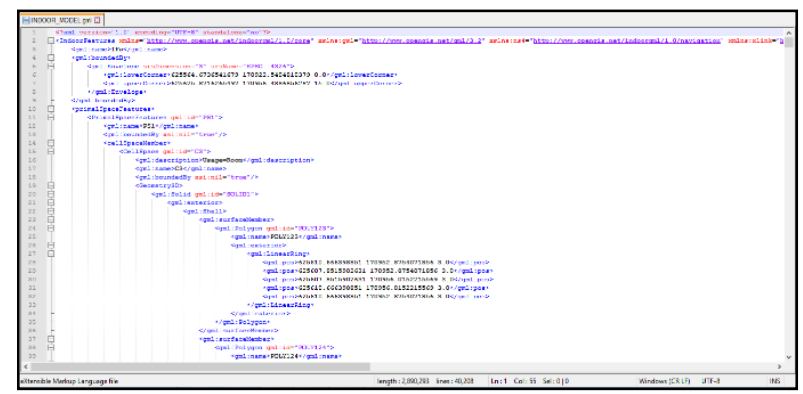

Figure 15. XML schema of indoor spatial information.

\subsection{Geospatial database based on LADM}

The geospatial represent LADM is developed as a database in ArcScene 10.3. At first, the database was developed in PostgreSQL and to be connected with the ArcGIS but a problem occurred during the connection. Hence, the database developed in the ArcScene itself. The tables involved are shown in Figure 16.

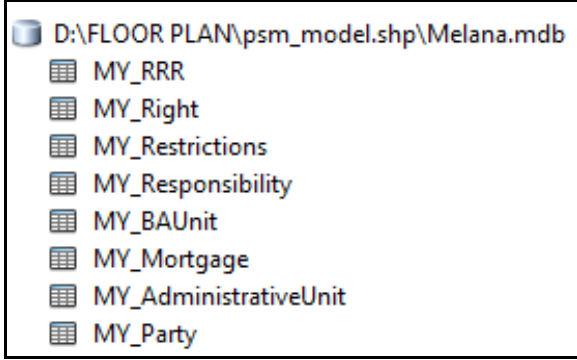

Figure 16. Object classes in database 


\subsubsection{Simple spatial query}

The figure below shows the query-based spatially click where the housing unit is selected and the attribute is shown.

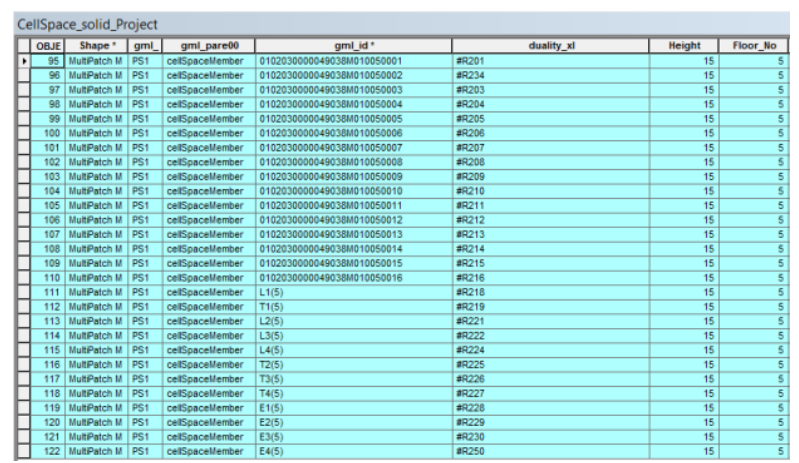

Figure 17. Query on spatial object

\subsubsection{Query using the unique ID (UFI)}

Selection by attributes by gml_id = $0102030000049038 \mathrm{M} 010020010$ where it will show all the information of the selected feature shown in Table 4.

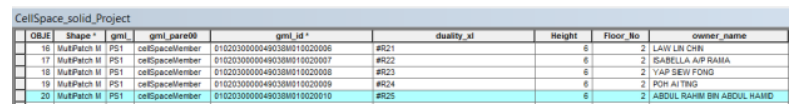

Table 4. Query using UFI

\subsubsection{Query using owner identification card number (IC)}

Selection by attributes by IC number $=961001016612$ where it will show all the information of the selected feature as shown in Figure 18.
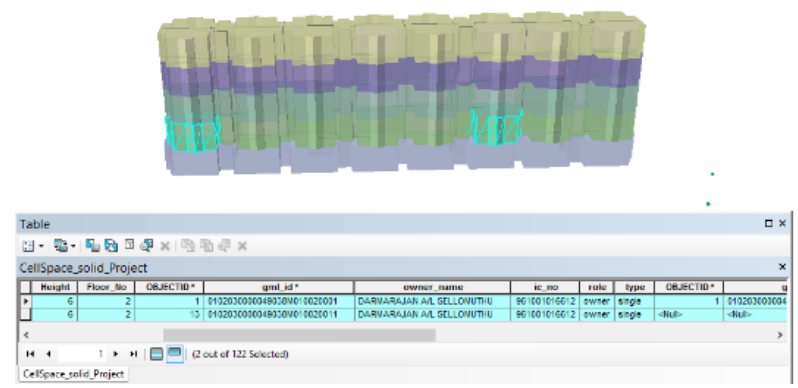

Figure 19. Query using IC

\subsubsection{Query according to floor}

Selection by attributes by floor no $=5$ where it will show all the information about the selected feature. Figure 19 shows the attribute query on Level 5.

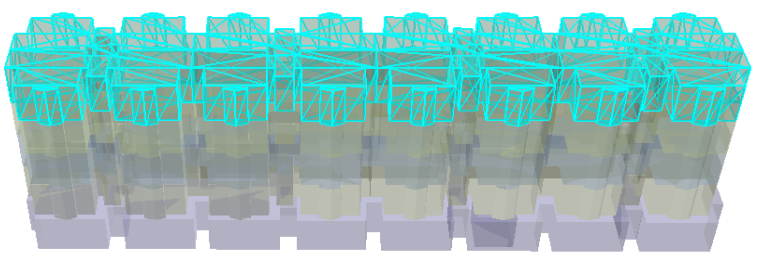

Figure 19. Query using floor number

\section{CONCLUSION}

This study proposed a conceptual data model based on the integration of LADM Edition II and IndoorGML for strata purposes. The research was done based on the problems related to handling the strata management along with their Rights, Restrictions, and Responsibility (RRR). Malaysia cadastre management has been used as a case study. The spatial and non-spatial components related to the model have been identified. This research consists of three-phases, which relate to the procedure of developing a data model based on the Malaysia LADM Country profile, building a prototype of a 3D model and link the database with a unique identifier called UFI. These data model can be implemented for better strata management in terms of the $2 \mathrm{D}$ and $3 \mathrm{D}$ strata registration in Malaysia.

\section{ACKNOWLEDGMENT}

I would like to thank my supervisor, Dr. Muhammad Imzan Bin Hassan from Department of Geoinformatics, Faculty of Built Environment and Surveying, University Technology Malaysia for all the guidance and supervision given to me in researching "The Integration of 3D spatial and non - spatial component for strata management". Besides that, thank you also to all my colleagues and family for the supports and guidance in completing my research.

\section{REFERENCES}

Alattas, A., Zlatanova, S., Van Oosterom, P., Chatzinikolaou, E., Lemmen, C., \& Li, K.-J. (2017). Supporting Indoor Navigation Using Access Rights to Spaces Based on Combined Use of IndoorGML and LADM Models. ISPRS International Journal of Geo-Information, 6(12), 384.

ECE, U. (1996). Land administration guidelines. With special reference to countries in transition. Geneva, Switzerland, United Nations/Economic Commission for Europe.

FIG. (1995). FIG Statement on the Cadastre In FIG Techical Report Publication 11, Federation International des Geometres, Commission 7 (Cadastre and Land Management). Canberra,Australia.

Hashim, M. N. (2018). 3D MODELLING TOWARDS STRATA REGISTRATION. XLII-4/W9.

Hassan , M. I., (2017). Integrated Three-Dimensional Cadastre Object Registration Framework Based on Cadastre Data Model. (Doctoral Dissertation), University Technology Malaysia (UTM)

Hassan, M. I., \& Rahman, A. A. (2011). Unique identifier for 3D cadastre objects registration. Paper presented at the 2 nd International Workshop on 3D Cadastres 16-18 November 2011, Delft, the Netherlands.

Jiyeong Lee, K.-J. L., Sisi Zlatanova, Thomas H. Kolbe, Claus Nagel, Thomas Becker. (2018a). IndoorGML, OGC Standard for Indoor Spatial Information. Retrieved from http://www.indoorgml.net/ 
Jiyeong Lee, K.-J. L., Sisi Zlatanova, Thomas H. Kolbe, Claus Nagel, Thomas Becker. (2018b). OGC®IndoorGML: Corrigendum.

Ki-Joune Li, H.-G. R., Hak-Cheol Kim, Jun Hee Lee, Joo-Ho Lee. (2016). Comparing CityGML and IndoorGML based on a use case at Lotte World Mall.

Kwong, D. W. L. ( 2011). What does it mean by Strata Title and will this effect the property value ? Retrieved from https://www.propertyguru.com.my/property-forum/what-

does-it-mean-by-strata-title-and-will-this-ef-710

Lemmen, C., Van Oosterom, P., \& Kalantari, M. (2018). Towards a New Working Item Proposal for Edition II of LADM. 331-354.

Sisi Zlatanova, K.-J. Lee., Lemmen, C and Van Oosterom,P. (2016). Indoor Abstract Spaces: Linking IndoorGML and LADM. 317-328.

Yusoff, M. Y. M. (2013). eKadaster: A Learning Experience for Malaysia.

Zulkifli, N. A. (2014). Adoption of Land Administration Domain Model for Land Administration in Malaysia (Master), University Technology Malaysia (UTM)

Zulkifli, N. A., Abdul Rahman, A., Jamil, H., Teng, C. H., Tan, L., Looi, K., .. . Van Oosterom, P. (2014). Towards Malaysian LADM country profile for 2D and 3D cadastral registration system. Paper presented at the Proceedings of the 25th FIG Congress: Engaging the challenges, enhancing the relevance, Kuala Lumpur, Malaysia, June 16-21, 2014.

Revised August 2019 